\title{
Die Nasionale Vlag van die Republiek van Suid-Afrika
}

W. Kroukamp*

\begin{abstract}
“ 'n Vlag is 'n sinnebeeld van volksbestaan. 'n Vlag kan die grootste geesdrif skep ... kan tot trane roer ... kan die diepste dryfvere tot handeling in beweging bring, en kan tot die edelste pogings besiel. Vir 'n vlag kan 'n volk leef, en kan hy veg en sterf.' - Dr D.F. Malan, 25 Mei 1926.
\end{abstract}

\section{Inleiding}

Suid-Afrika het sy eie Nasionale Vlag op $31 \mathrm{Mei}$ 1928 amptelik in gebruik geneem met ' $n$ seremoniële hysing voor duisende juigende Suid-Afrikaners by die Parlementsgebou in Kaapstad. Hysingsplegtighede het landwyd plaasgevind. In Pretoria het die verrigtinge met militêre eerbewys voor die Uniegebou plaasgevind. Suid-Afrika kon sigbaar sy verskyning maak onder die vrye nasies van die wêreld nadat hy in 1926 ná die Statuut van Westminister ' $n$ erkende soewereine onafhanklike staat geword het.

Hoewel sprake van 'n eie nasionale vlag vir die Unie van Suid-Afrika ná Uniewording in 1910 by geleenthede na vore gekom het, is eers in 1926 met die eerste daadwerklike amptelike stappe daartoe begin. Dit sou egter twee jaar duur voordat die Nasionale Vlag sy verskyning kon maak twee jaar van stryd, wat hoofsaaklik gevoer is om ooreenstemming tussen die volksgroepe en hul verteenwoordigers in die Parlement te bereik.

Die Vlagwet is aan die einde van 1927 aanvaar ingevolge waarvan die Unievlag as Nasionale Vlag aanvaar en erken is, maar die Union Jack moes nog by sekere geleenthede naas die Unievlag vertoon word as teken van die Unie se Statebondsverbintenis.

Dié toestand het byna dertig jaar voortgeduur totdat die Unievlag in 1957 aanvaar is as die enigste landsvlag van Suid-Afrika.

Met Republiekwording op 31 Mei 1961 het die Unievlag onveranderd die Republiekvlag geword en wapper hy steeds as die algemeen erkende simbool van eie nasieskap in SuidAfrika.

\section{Herkoms van die Nasionale vlag}

Die krygsmagte van lande het 'n groot rol gespeel in die ontwikkeling van nasionale vlae en die tradisie daaraan verbonde. Vroeër was dit

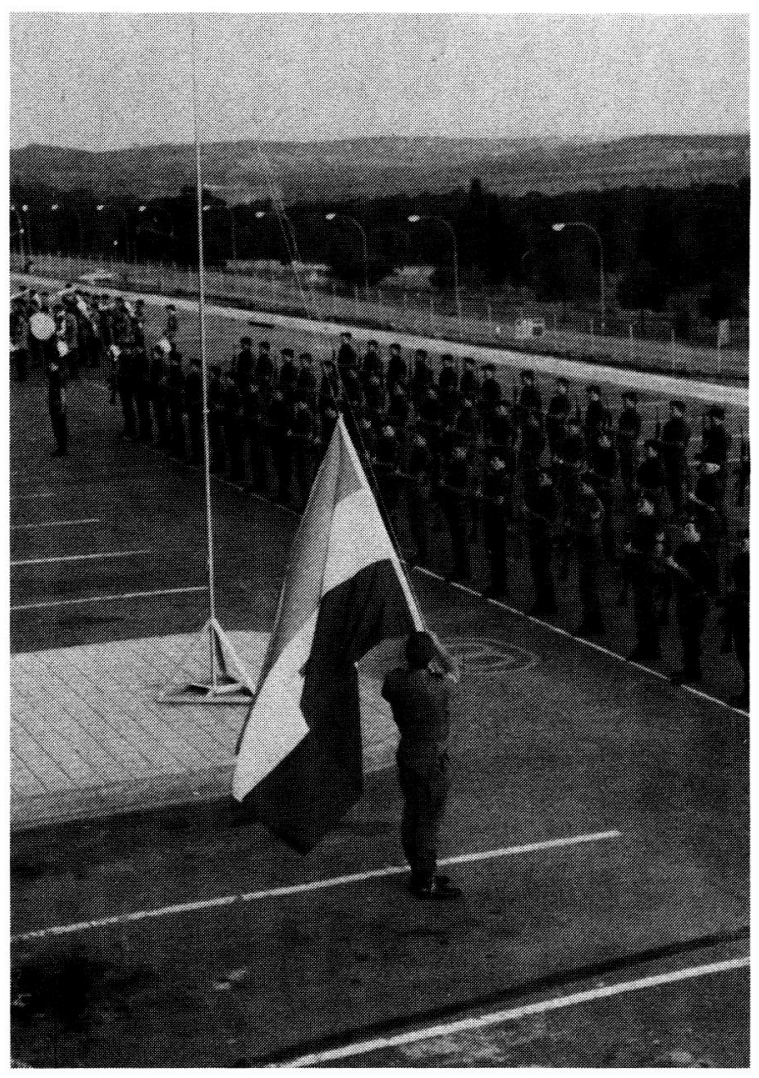

'n Vlaghysingsseremonie op Voortrekkerhoogte. Op 31 Mei 1928 is die Nasionale Vlag van Suid-Afrika amptelik in gebruik geneem met 'n seremoniële hysing by die Parlementsgebou in Kaapstad

die visuele simbool waardeur die tradisie, trots en dade van 'n leëreenheid na vore gebring is.

In hul vroegste vorm is vlae en standaarde gebruik vir die uitsluitlike doel om vriend en vyand in die hitte van die stryd van mekaar te onderskei.

Dit was byvoorbeeld die gebruik van die ou Romeine om die simbool van die Romeinse keiserlike gesag, wat aan 'n stok vasgemaak was, hoog bo die leërskare uit te hou. Sodoende is dit tot die uiterste toe verdedig sodat dit nie in die hande van die vyand sou val nie. Later is 'n doek aan die stok vasgemaak en die simbool is op die doek geskilder. 


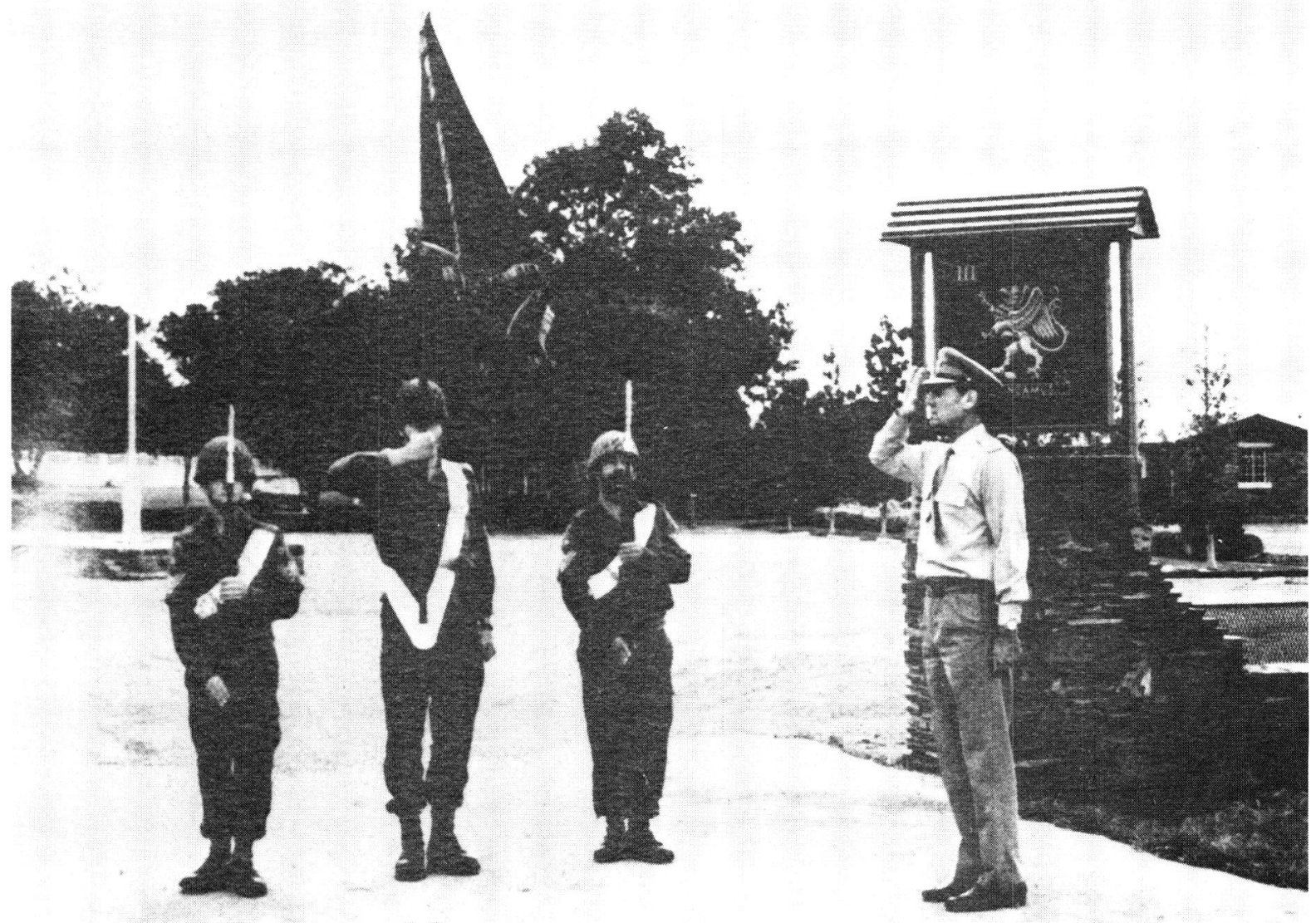

Vlae en standaarde was vroeër die visuele simbool waardeur die tradisies, trots en dade van 'n leëreenheid na vore gebring is

Hierdie versierde doeke was vroeër net simbole van leëreenhede en nie van volke nie. Soldate van 'n land wat gedurende die Middeleeue onder die banier van hul aanvoerder geveg het, het dit mettertyd as die land- of volksimbool beskou.

Die gevolgtrekking kan dus gemaak word dat die nasionale vlag op twee maniere ontstaan het: uit skildwapens van aanvoerders en as vryheidsimbole. Dit is egter in die RSA se vlag verenig: Die oranje-wit-en-blou vlag was die vryheidsvlag van die Protestantse Watergeuse asook die simbool van hul aanvoerder, Prins Willem van Oranje, wat 'n rewolusie teen die Katolieke Spaanse bewind gelei het.

Die oranje-wit-en-blou vlag dagteken uit die sewende dekade van die sestiende eeu. Dié vlag het later die volksimbool en vlag van die Nederlandse Republiek geword. Dit was dié vlag wat Jan van Riebeeck die 'Prinsevlagge' genoem en met sy landing aan die Kaap in 1652 hier geplant het.

\section{Simbool van onafhanklikheid}

Met die tweede Britse besetting van die Kaapko-
Ionie in 1806, het die Engelse bewind sy eie simbole op Afrikaanse bodem oorgeplant, maar vir 'n groot deel van die bevolking het dié nuwe simbole geen patriotiese gevoelswaarde gehad nie.

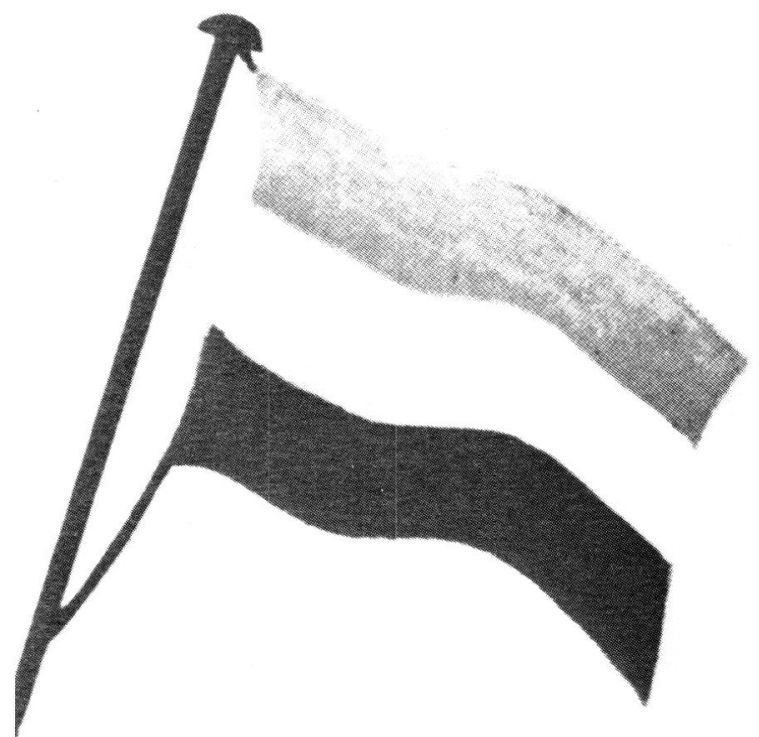

Die vryheidsvlag van die Protestantse Watergeuse en hul aanvoerder, Prins Willem van Oranje, wat' $n$ rewolusie teen die Katolieke Spaanse bewind gelei het. Die oranje-wit-en-blou vlag of 'Prinsevlag' is later as basis gebruik vir die ontwerp van ons Nasionale Vlag 
Die eerste tree na onafhanklikheid is geneem toe groepe trekkers Oos-Kaapland verlaat het en hulle in die Republiek Natalia gevestig het. 'n Vlag, bestaande uit rooi, wit en blou met 'n puntige vorm in die rigting van die stok, is ontwerp.

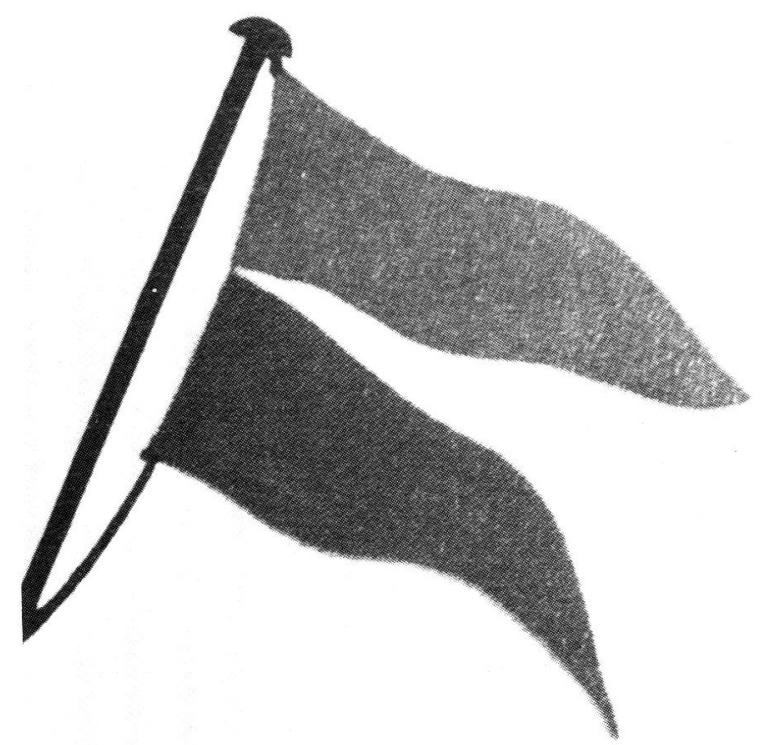

Die vlag van die Republiek Natalia (1839-1843) - die eerste vlag wat in Suid-Afrika ontwerp is. Dit is rooi, wit en blou met 'n puntige vorm in die rigting van die stok

Die onttrekking van Engelse troepe in Desember 1839 uit die hawe van Port Natal (nou Durban) is deur die Voortrekkers as 'n erkenning van hul onafhanklikheid beskou. Hulle het kort daarna die nuwe vlag gehys en 'n salvo ter viering van die geleentheid afgevuur

Die Vrystaters het voor dieselfde probleem te staan gekom, naamlik dat die onafhanklikheid van hul nuwe staat ook deur 'n nuwe vlag gesimboliseer moes word. Die Vrystaatse Republiek het ' $n$ beroep op die Huis van Oranje gedoen om ' $n$ vlag aan hulle te skenk. Na vele beraadslaging het die Nederlandse kabinet besluit op ' $n$ vlag met vier horisontale oranje bane tussen vyf wit bane en 'n rooi-wit-en-blou kanton in die bohoek. Die nuwe vlag is op 23 Februarie 1857 amptelik in Bloemfontein onthul. Dié vlag het onveranderd die staatsvlag van die Oranje-Vrystaat gebly tot aan die einde van die Republiek in 1902.

In die Zuid-Afrikaansche Republiek is die staatssimbole deur ' $n$ volksraadsbesluit ingestel. Die horisontale kleure van die vlag sou rooi, wit en blou wees met 'n groen streep langs die stok. Die Vierkleur is in 1857 in gebruik geneem, maar met die eerste Britse besetting van Transvaal afgeskaf en is na die herstel van die onafhanklikheid van die Republiek weer herstel. Op 31 Mei

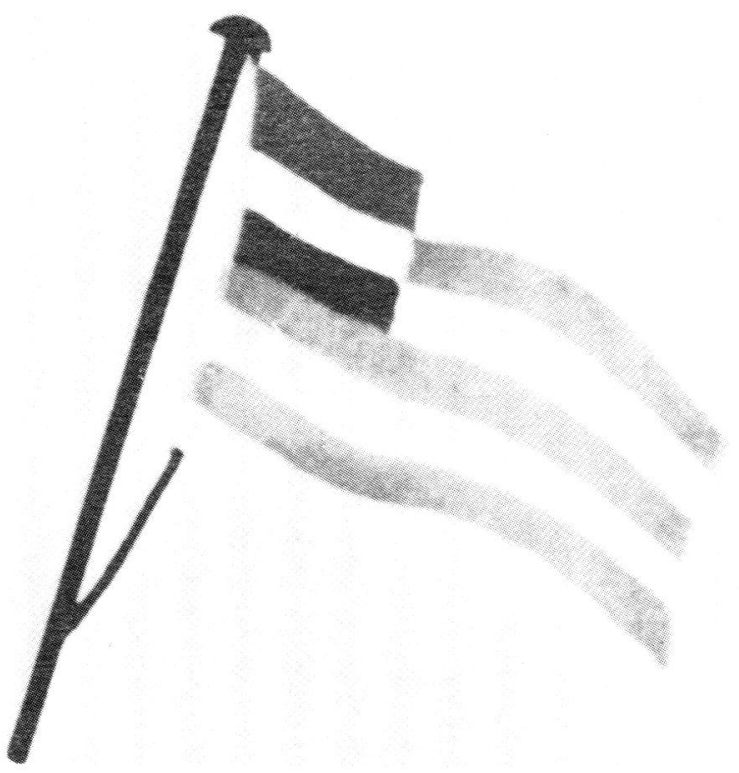

Die amptelike vlag van die Oranje-Vrystaat (1854-1902). Die Huis van Oranje het die vlag met vier horisontale oranje bane tussen vyf wit bane en 'n rooi-wit-en-blou kanton in die bohoek, aan die Vrystaat geskenk

1902 is die Vierkleur in Vereeniging vir die laaste keer gestryk. Voortaan sou die Union Jack oor Suid-Afrika wapper.

Ná Uniewording in 1910 het die regering ' $n$ vlag aanvaar met die Union Jack in die boonste hoek en die wapen van die Unie in die middel. Vandag staan die Union Jack langs die Vrystaatse en Transvaalse vlae in die middel van die Nasionale Vlag as simbool van die aandeel wat Britte en Engelssprekende Suid-Afrikaners in die geskiedenis en staatkundige ontwikkeling gehad het.

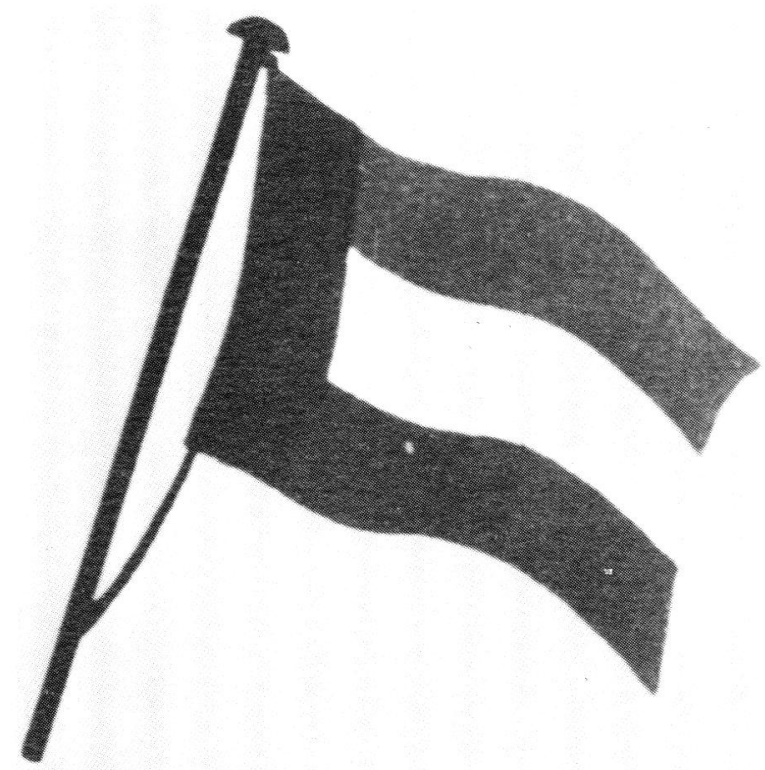

Die vlag van die Zuid-Afrikaansche Republiek. Die Vierkleur, bestaande uit rool, wit en blou met 'n groen streep langs die stok, is in 1857 in gebruik geneem 


\section{Die Vlagstryd}

Met die groei van die selfstandigheid en onafhanklikheid van die Unie, het die behoefte aan 'n eie nasionale vlag duideliker geword. Die vraagstuk van 'n nasionale vlag was 'n belangrike punt op die agenda van besprekings in die Parlement, wat uiteindelik in 1921 tot die vereniging van die Suid-Afrikaanse en Verenigde Party gelei het. Die kwessie van 'n nasionale vlag het egter eers in 1924 met die bewindsaanvaarding van 'n nuwe regering, aandag geniet.

Hoewel die eertydse Minister van Binnelandse Sake, dr D.F. Malan, in 1925 'n wetsontwerp by die Parlement ingedien het, wat die Goewerneurgeneraal magtiging gegee het om ' $n$ beskrywing van die ontwerp van die nasionale vlag in die Staatskoerant bekend te maak, sou die eerste daadwerklike amptelike stappe eers in 1926 begin.

Die bevolking van die Unie was in dié tyd emosioneel-polities gespanne - die stryd om 'n eie vlag het ' $n$ hewige politieke storm in die Unie veroorsaak. Meningsverskille oor die insluiting of weglating van die Union Jack het tussen die politieke partye en bevolkingsgroepe ontstaan. Dié stryd om 'n erkende simbool van eie nasieskap sou twee jaar duur voordat ooreenstemming tussen die volksgroepe en tussen hulle verteenwoordigers in die Parlement bereik is.

In 1926 benoem die Unieregering ' $n$ Vlagkommissie wat die verskillende ontwerpe van die vlag moet oorweeg of verwerp. Die kommissie is bygestaan deur heraldikusse wat die tegniese sy van die ontwerpe hanteer het.

\section{Die Republiekvlag - 'n Simbool van Eenheid}

Die algemene grondslag wat vir die Suid-Afrikaanse vlag gestel was, was dat dit moes getuig van eenheid en 'n juiste weergawe van SuidAfrika se staatsregtelike posisie moes wees.

Verskeie ontwerpe vir die nasionale vlag is voorgestel en ooreenstemming is eindelik bereik met die ontwerp wat vandag nog die Nasionale Vlag is. Die 'Van Riebeeckvlag' - oranje, wit en blou is gekies en die Union Jack, die vlae van die Republiek de Oranje-vrÿstaat en dié van die Zuid-Afrikaansche Republiek is as skild op die middelste wit baan aangebring.

Die Nasionale Vlag is in die Vlagwet van 1927 (wet no. 40, 1927) soos volg beskryf: 'Drie hori- sontale bane ewe wyd, van bo na onder oranje, wit en blou; in die middel van die wit baan die gewese vlag van die Oranje-Vrystaat vertikaal ten volle oopgesprei afhangende, met die Union Jack horisontaal daaraan grensende ten volle oopgesprei in die rigting van die vlagpaal, en die gewese Transvaalse Vierkleur horisontaal daaraan grensende ten volle oopgesprei weg van die vlagpaal af, op gelyke afstand van die kante van die wit baan. Die vlae sal almal ewe groot wees, en hul vorm sal proporsioneel dieselfde as dié van die Nasionale Vlag wees.'

\section{Die Volle Verwesenliking Van Eie Nasieskap}

Reeds twee maande voor die ingebruikneming van die Nasionale Vlag is dit op 30 Maart 1928 in Havanna, Kuba gehys. Mnr Eric Louw het vir dié geleentheid ' $n$ vlag laat vervaardig. Die Nasionale Vlag is dus eers in die buiteland bekendgestel voordat dit op 31 Mei 1928 op eie bodem in gebruik geneem is.

Die amptelike vlaghysing op 31 Mei 1928 kan as 'n mylpaal in die Suid-Afrikaanse geskiedenis beskou word. Die verkryging van die Nasionale Vlag was ' $n$ belangrike stap in die rigting van staatkundige selfstandigheid, vryheid en onafhanklikheid.

Die groot plegtigheid het in Kaapstad plaasgevind, waar die Nasionale Vlag saam met die Union Jack onder kanongebulder, klokkegelui

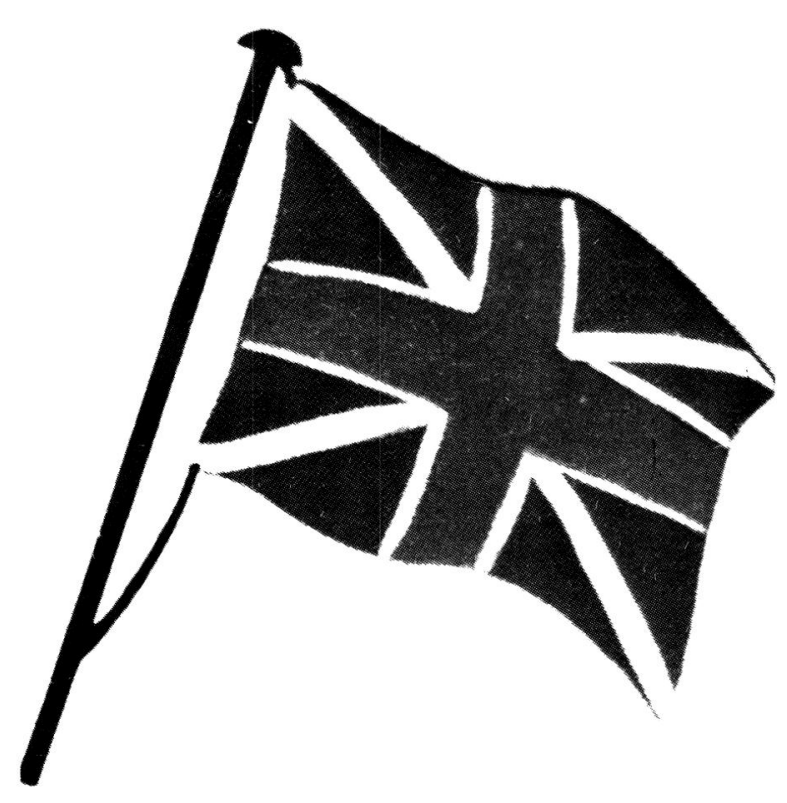

Die Union Jack is tot Republiekwording in 1961 saam met die Nasionale Vlag gehys, maar ná 1957 is die Nasionale Vlag as die enigste landsvlag aanvaar 
en trompetgeskal by die Parlementsgebou gehys is. Die Union Jack is tot Republiekwording in 1961 saam met die Nasionale Vlag gehys, maar sedert Suid-Afrika in 1957 die Gemenebes verlaat het, is die Nasionale Vlag as die enigste landsvlag in Suid-Afrika aanvaar.

Vandag word die Nasionale Vlag landwyd by skole, op herdenkingsdae, militêre parades, begrafnisse en by spesiale geleenthede in opdrag van die Eerste Minister gebruik. Die gewoonte om die vlag op nasionale feesdae of ander feestelike gebeurtenisse by woonhuise te laat wapper of in die voortuin voor die huis te hys, neem vandag al hoe meer onder Suid-Afrikaners toe.

By militêre begrafnisse, waar ' $n$ afgestorwe lid van die Suid-Afrikaanse Weermag vereer word, moet die kis met die Nasionale Vlag gedrapeer word, met die wapperkant aan die voetenent en die oranjestreep regs van die kis, van die kop na die voetenent van die kis gesien.

\section{Slotopmerkings}

Eerbetoon aan 'n nasionale vlag dagteken uit die verlede en is deur die geslagte heen getrou gehuldig. In Suid-Afrika het die burgers aan die
Kaap, die Voortrekkers en die burgers van die republieke dié tradisie voortgesit en aan ons geslag oorgedra. Ons bekende volksdigter C.J. Langenhoven het die Nasionale Vlag in sy 'Vlaglied' besing en 'n dieper betekenis daaraan gegee:

Nooit hoef jou kinders wat trou is te vra: Wat beteken jou vlag dan, Suid-Afrika? Ons weet hy's die seël van ons vryheid en reg Vir naaste en vreemde, vir oorman en kneg; Die pand van ons erf'nis, geslag op geslag; Om te hou vir ons kinders se kinders wat wag; Ons nasie se grondbrief van eiendomsland Uitgegee op gesag van die Hoogste se hand. Oor ons hoof sal ons hys, in ons hart sal ons dra, Die vlag van ons eie Suid-Afrika.

* Mej. W. Kroukamp, Nas. Dipl. in Joernalistiek, is verbonde aan die Militêre Informasieburo van die SAW.

\section{Bibliografie}

1. Davies, T.S. Kmdt, 'Seremonieel, tradisie en gebruik: goeie gewoontes!' Paratus, Februarie 1976.

2. Military Custom and Traditions, Paratus, Januarie 1974

3. National Symbols, The Official Yearbook of the Republic of South Africa 1982, Johannesburg.

4. Pama, C., Die vlae van ons land, Kaapstad, 1976.

5. SAW Argief, Pamflette, Houer 234, Nr. 4843 (Voorskrifte betreffende die voer van die Nasionale Vlag van Suid-Afrika.) 